\title{
MARÍA Victoria Utrera TORREMOCHA: Historia y teoría del verso libre. Padilla Editores \& Libreros, Sevilla, 2001.
}

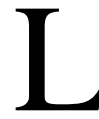

a autora del presente trabajo lo es también de una monografía sobre el poema en prosa publicada dos años antes, Teoría del poema en prosa, Sevilla, Universidad, 1999. Parece, pues, sentir atracción por el amplio espacio de las formas que ilustran no tanto el problema de la poesía sin verso, sino el más complejo de los límites entre verso y prosa, especialmente tal como se plantean en la literatura contemporánea desde el siglo XIX. La introducción al libro de 1999 plantea la cuestión, centrada en el poema en prosa; allí se verá cómo es inevitable la referencia al verso libre, pues, como ya dijera Pedro Henríquez Ureña, en palabras que reproduce la autora (p. 13), «la separación entre verso y prosa no es absoluta».

Ahora aborda la cuestión desde el campo del verso y sitúa su estudio en la tradición que incluye el conocido libro de Isabel Paraíso (1985) sobre el verso libre hispánico, y la sección de 50 páginas que más recientemente consagró Oldrich Belic al verso libre en su Verso español y verso europeo (Bogotá, Instituto Caro y Cuervo, 2000, pp. 552-602), que interesan especialmente por las referencias a la versología eslava.

Para hacernos una idea más precisa del significado de la obra de María Victoria Utrera, siguen unas notas de resumen de la lectura del trabajo. El capítulo I, "Versificación irregular y verso libre”, trata como cuestiones más destacables: el lugar del verso libre en propuestas y consideraciones generales sobre la versificación irregular (por ejemplo, las de P. Henríquez Ureña, T. Navarro Tomás o Isabel Paraíso); el problema de la versificación semilibre, el versículo, la línea poética, la pluralidad de acepciones de verso libre. Este mismo capítulo -que, como se ve, trata de centrar el concepto y el origen del verso libre-, a partir de la página 36, incluye una breve historia de los antecedentes del fenómeno internacional del versolibrismo; y, junto 
a las inevitables menciones de los ejemplos de la literatura inglesa y francesa, hay otras, menos familiares entre nosotros, a las literaturas alemana (pp. 38-41), rusa (pp. 43-44), o italiana (p. 45). No falta la indagación en los orígenes del verso libre en intentos de ampliación de la métrica también española, con una amplia discusión sobre las formas de versificación irregular. La autora se alinea con quienes piensan que el verso libre moderno no supone una recuperación de la tradición española de versificación irregular, sino una forma nueva que tiene sus raíces en el cambio de ambiente métrico de fines del siglo XVIII, y sobre todo del romanticismo y postromanticismo (pp. 60-61). Estamos de acuerdo con esta forma de plantear la cuestión, pues para nosotros no hay duda de que el verso moderno español, pero también el de otras literaturas europeas, empieza a conformarse en el siglo XVIII. Y en el ambiente entonces creado es en el que más tarde aparecerá el verso libre.

El capítulo II, "Walt Whitman y las corrientes simbolistas y modernistas", atiende a las primeras manifestaciones del verso libre consideradas canónicas. Importante es el esfuerzo que hace María Victoria Utrera para trazar las líneas de la tradición versicular whitmaniana en la literatura francesa (pp. 69-71) o en la española (pp. 71-74). La otra base del versolibrismo europeo es la constituida por el núcleo simbolista francés, y de ella trata a continuación (pp. 74-97), con referencias al alejandrino renovado por Rubén Darío (pp. 77-79), o a una cuestión tan conocida por la autora como es la del poema en prosa. «Es indudable - dice- la filiación del verso libre simbolista con la prosa poética y con el poema en prosa, de ahí que, como se verá después, el ritmo del verso libre sea en muchas ocasiones un ritmo basado en la sintaxis y la imagen» (p. 80). El resto del capítulo está dedicado a la expansión del verso libre, especialmente en la literatura española (pp. 99-124), después de una breve alusión a la literatura rusa y brasileña (pp. 97-99). Imposible es entrar en los detalles de una riquísima documentación de tipo teórico que completa el tratamiento que del asunto ya se hiciera en otros trabajos anteriores de distintos autores. Sí quiero señalar, como un índice de la complejidad e implicaciones de todo tipo que pueden encontrarse en cualquier página del libro, cómo la autora se desvincula de la consideración de la versificación de cláusulas inaugurada por el colombiano José Asunción Silva como forma versolibrista (pp. 115-116).

Ofrece en el capítulo III, "El verso libre de la vanguardia y otras manifestaciones versolibristas", un rico panorama de formas 
relacionadas con las vanguardias, aparte de las del mundo hispánico. Por ejemplo, las de la versificación acentual rusa, o el versolibrismo de la poesía inglesa. Llega el panorama histórico hasta la poesía reciente en español: Luis A. De Villena, por ejemplo, y su llamada a la creación de un nuevo verso libre (p. 179). Pero también se estudia, por ejemplo, a Juan Ramón Jiménez (pp. 150-157), la generación del 27 (pp. 155-161), la postguerra o la poesía visual (pp. 166-167). El punto de vista adoptado es esencialmente histórico, sin faltar la recensión de las opiniones de poetas sobre el verso libre: poetas de los 70 o de los 80 (pp. 171-172).

El capítulo IV, "Ritmo interior y ritmo de pensamiento", se centra en cuestiones más teóricas, pues intenta indagar en la naturaleza del ritmo del verso libre. Para ello analiza opiniones y propuestas de autores bien conocidos, como Amado Alonso, Samuel Gili Gaya, T. Navarro Tomás, Dámaso Alonso, Rafael Lapesa, F. López Estrada, Kurt Spang, P. Jauralde Pou, F. Lázaro Carreter, C. Bousoño, E. Alarcos. El problema de encabalgamiento y verso libre, o la teoría formalista del ritmo, son ejemplos de la riqueza de cuestiones implicadas en el estudio del verso libre.

El capítulo V, “La cuestión tipográfica. Verso y prosa”, entra en un asunto de gran importancia. No es raro que los analistas del verso libre, por encima de la disposición gráfica, quieran encontrar un esquema fónico emparentado con las formas del verso tradicional. Recuérdese el recurso frecuentísimo a la base endecasilábica para la explicación de muchas manifestaciones de verso libre moderno (Aleixandre ofrece los ejemplos más frecuentemente estudiados). Pero más allá del enunciado, este capítulo plantea cuestiones esenciales de la definición del verso libre, que, aparte de lo tipográfico, ideológico o sentimental, debe centrarse en la ruptura con el principio de la igualdad silábica: «Es la igualdad silábica, sobre todo, el factor rítmico con el que el versolibrismo pretende romper, igualdad silábica que, en el ámbito francés, iba unida a una serie de reglas que alejaban la pronunciación del verso del lenguaje hablado» (p. 229).

A partir del criterio métrico (silábico) agrupa en tres las explicaciones del verso libre: 1 ) verso libre aliterativo o con rima; 2) verso libre acentual; y 3) verso libre que gira alrededor de una medida y sus medidas afines (p. 229). En la discusión de este último tipo, que es el "de mayor importancia en la poesía española", es cuando se plantea el estudio de la base endecasilábica antes mencionada, por ejemplo, con la aparición de nombres bien conocidos en relación con 
el tema, como C. Bousoño o F. Lázaro Carreter. Una lista de autores que han visto la repetición de esquemas métricos en el verso libre, se encuentra en p. 239.

Reproduzco un párrafo que describe muy bien el nudo del problema del verso libre: «A la luz de las opiniones recogidas sobre el verso libre es evidente que el principal problema para su definición tiene su origen en la variedad versolibrista y en sus formas afines, así como en las sólidas interrelaciones que se dan con la tradición métrica regular. Hay que descartar, por lo tanto, un único concepto de verso libre válido para explicar toda la gama versolibrista. Las tipologías existentes niegan, sin duda, la opinión de que haya tantos poemas libres como autores versolibristas y de que, en consecuencia, el estudio sistemático de verso libre sea sólo una quimera» (p. 252). Así se justifica la relación de tipologías del verso libre que encontramos en las páginas siguientes (pp. 252-259): de Robert de Souza, Tomachevski, H. Morier, Beltrami, N. Tomás, I. Paraíso.

A continuación empieza el tratamiento de la relación del verso libre y la prosa. No hay que decir que es inevitable la referencia al poema en prosa (p. 259). Hay autores que aproximan el verso libre a la prosa (Benoît de Cornulier, o Beltrami, entre los modernos más conocidos), otros, como O. Belic, defienden la existencia de normas rítmicas propias del verso libre. De cualquier forma, la segmentación específica es lo que separa el verso libre de la prosa. En la importancia de la segmentación coincide O. Belic con Tinianov o Tomachevski, pues se trata de marcar otro tipo de función diferente de la de la prosa. La tipografía es un indicador pragmático (p. 273). La semiótica representada por I. Lotman tiene en cuenta también la disposición tipográfica como señal que predispone a una lectura.

El capítulo incluye en su última parte consideraciones sobre la importancia del contexto histórico para entender el verso libre, lo que hace basándose en la autoridad de Mukarovsky, y le lleva a la estética de la recepción. En este ambiente surgen afirmaciones, con aire de tesis general, tan claras como: «Las diferentes opiniones sobre el verso libre y su consideración como verso o prosa dependen, pues, de los lectores y de sus expectativas» (p. 274). En definitiva, la innovación versolibrista es un problema estético y no exclusivamente métrico, como señala en el párrafo final, que es una especie de resumen y conclusión de este capítulo. Capítulo que nos parece ser el que entra más directamente en lo que es una definición del verso libre tal como la piensa María Victoria Utrera Torremocha. 
El último capítulo, "El verso libre en la poesía española de los últimos treinta años”, es una descripción utilísima de las tendencias versolibristas actuales. Sorprende, contra una idea que parece ir inseparablemente unida a la poesía moderna, que el 68\% del corpus analizado (constituido por unos 950 poemas de cuatro antologías) son regulares; el 12\% corresponde a verso libre atenuado de base rítmica interrumpida; y el 20\%, verso libre más prosaico o que mezcla ritmos conocidos (pp. 292 y 314).

Hay que destacar los ejemplos de análisis de poemas concretos de distintos poetas (Miguel D’Ors, Luis García Montero, Rosa Romojaro, Juan Luis Panero, Pere Gimferrer, Antonio Carvajal, Andrés Sánchez Robayna, Leopoldo María Panero, Luis Antonio de Villena, Blanca Andreu, Roger Wolfe). Estos análisis son imprescindibles para demostrar la construcción de muchos versos sobre base tradicional, y la opción personal en la comprensión de formas ambiguas. Véase, a este respecto, en otro capítulo anterior, el comentario de la calificación de algún poema fundada en una escansión errónea (p. 241). Entre las conclusiones se lee: «El retorno a la métrica tradicional es generalizado en la poesía actual y, con él, el claro descenso del verso libre arrítmico» (p. 315). Seguramente esta conclusión será válida también si se analiza un grupo de poetas no exclusivamente españoles.

La aportación de María Victoria Utrera Torremocha, en el contexto de los estudios sobre el verso libre, debe ser destacada en los siguientes aspectos, me parece: una consideración de gran número de teorías referidas al verso libre en las principales literaturas europeas; una indagación detenida en los orígenes de las formas de verso libre en las mencionadas literaturas; un análisis detallado de cuestiones centrales de la discusión, como son las del ritmo y las de la tipografía; y la descripción de las últimas tendencias en las manifestaciones del verso libre en una muestra elegida de la poesía española última. Añádase la apertura de la consideración de la métrica más allá de lo descriptivo (que es imprescincible, y siempre hay que dar por supuesto) a lo estético e histórico, como se ha visto en los frecuentes apoyos en escuelas vigentes en el pensamiento teórico actual de la literatura. Con este trabajo, el estudio del verso libre cuenta con los apoyos teóricos firmes para las imprescindibles descripciones de manifestaciones concretas que dibujen el cuadro de sus formas y vigencia. 